\title{
Relationship of N-Terminal fragment of Pro B-Type Natriuretic Peptide and Copeptin with Erythrocytes-Related Parameters: A Population-Based Study
}

Francisco Javier Ruperti Repilado, MD ${ }^{1,2}$, Stefanie Aeschbacher, MSc ${ }^{1,2}$, Matthias Bossard, $M D^{2,3}$, Tobias Schoen, MD ${ }^{1,2}$, Rebecca Gugganig, BMed ${ }^{2}$, Jan Gerrit van der Stouwe, MD ${ }^{1,2}$, Philipp Krisai, $M D^{1,2}$, Thomas Kofler, $M D^{1,2}$, Andreas Buser, $M D^{4}$, Martin Risch, $M D^{5,6}$, Lorenz Risch, MD MPH ${ }^{5,7,8}$, Christian Mueller, $\mathrm{MD}^{1,2,3}$, David Conen, MD MPH ${ }^{1,2,3}$

1 Internal Medicine Division, Department of Medicine, University Hospital Basel, Petersgraben 4, 4031 Basel, Switzerland

2 Cardiovascular Research Institute Basel, University Hospital Basel, Switzerland

3 Cardiology Division, Department of Medicine, University Hospital Basel, Petersgraben 4, 4031 Basel, Switzerland

4 Hematology Division, Department of Medicine, University Hospital Basel, Switzerland

5 Labormedizinisches Zentrum Dr. Risch, Schaan FL

6 Division of Laboratory Medicine, Kantonsspital Graubünden, Chur, Switzerland

7 Division of Clinical Biochemistry, Medical University Innsbruck Austria

8 Private University, Triesen, FL

Short title: NT-proBNP, Copeptin and Hemoglobin

Address for correspondence:

David Conen, MD MPH

Department of Medicine, University Hospital Basel

Petersgraben 4, 4031 Basel, Switzerland

Phone: +41 6132866 96; Fax +4161 2655734

E-mail: david.conen@usb.ch

Word count of the manuscript: 2283 


\begin{abstract}
BACKGROUND: Plasma levels of natriuretic peptides (NP) have been inversely related to hemoglobin $(\mathrm{Hb})$ concentration in prior studies. However, the mechanism underlying this association remains unclear. We aimed to obtain further insights into potential mechanisms for this correlation in a cohort of healthy adults.
\end{abstract}

METHODS: A population-based study was performed among 2113 healthy adults aged 25 to 41 years. Relationships of N-Terminal fragment of Pro B-Type Natriuretic Peptide (NTproBNP) or copeptin with volume-dependent $(\mathrm{Hb}$, hematocrit $(\mathrm{Hct})$, erythrocyte count $(\mathrm{Ec})$, mean corpuscular $\mathrm{Hb}$ concentration (MCHC)) and volume-independent (mean corpuscular volume $(\mathrm{MCV})$, mean corpuscular $\mathrm{Hb}(\mathrm{MCH}))$ erythrocyte-related parameters were assessed using sex-specific multivariable linear regression analyses.

RESULTS: Median age was 36.7 years. Median NT-proBNP (ng/L) levels were 49.5 and 20 among women and men, respectively $(\mathrm{p}<0.0001)$. Mean (standard deviation) $\mathrm{Hb}(\mathrm{g} / \mathrm{L})$ levels were 130.1(9.1) and 149.7(8.6) among women and men, respectively ( $\mathrm{p}<0.0001)$. Among men, multivariable adjusted $\beta$-coefficients (95\% confidence interval) for NT-proBNP were $1.68(-2.36 ;-1.01), \mathrm{p}<0.0001$ for $\mathrm{Hb} ;-0.38(-0.57 ;-0.20), \mathrm{p}<0.0001$ for Hct; $-0.06(-0.09 ;-$ $0.04), \mathrm{p}<0.0001$ for $\mathrm{EC} ;-0.78(-1.50 ;-0.07), \mathrm{p}=0.03$ for MCHC; $0.26(-0.04 ; 0.56), \mathrm{p}=0.09$ for $\mathrm{MCV}$ and $0.03(-0.08 ; 0.14), \mathrm{p}=0.61$ for $\mathrm{MCH}$. For copeptin, these relationships were $1.36(0.39 ; 2.32), \mathrm{p}=0.006 ; 0.41(0.15 ; 0.68), \mathrm{p}=0.002 ; 0.06(0.02 ; 0.09), \mathrm{p}=0.002 ;-0.17(-$ $1.19 ; 0.86), \mathrm{p}=0.75 ;-0.12(-0.55 ; 0.31), \mathrm{p}=0.58$ and $-0.05(-0.21 ; 0.10), \mathrm{p}=0.52$. Similar results were observed among women. 
CONCLUSIONS: We found significant relationships of NT-proBNP and copeptin with volume-dependent but not volume-independent erythrocyte-related parameters, suggesting that hemodilution may at least in part explain these associations.

Keywords: Natriuretic peptides, copeptin, hemoglobin, hemodilution, population-based, epidemiology. 


\section{Introduction}

Plasma levels of natriuretic peptides (NP) have been established as reliable diagnostic and prognostic markers in heart failure (HF) patients and their plasma levels directly correlate with the degree of ventricular dysfunction (1-3). NP are synthesized by atrial and ventricular cardiomyocytes, primarily as a response to increased myocardial wall stress. Accordingly, systemic effects of NP include the regulation of intravascular volume by promoting sodium and water excretion as well as systemic vasodilation (4-7).

Prior studies have suggested an inverse relationship of NP with hemoglobin $(\mathrm{Hb})$ levels $(8-$ 10). However, the mechanisms underlying these relationships are currently unknown. As prior studies were conducted in middle-aged to elderly individuals, confounding by comorbidity could be a partial explanation. In addition, given the physiologic properties of natriuretic peptides, hemodilution may also play an important role, as $\mathrm{Hb}$ is a volumedependent parameter. Interestingly, Anand et al. previously showed that anemic HF patients had a higher prevalence of volume overload related HF symptoms and signs compared to HF patients without anemia (11), a finding that would be in line with the above mentioned hypothesis. Finally, if the hemodilution hypothesis was correct, then positive associations should be observed between $\mathrm{Hb}$ or hematocrit (Hct) and markers related to vasopressin metabolism, such as copeptin $(12,13)$.

In order to test the hypothesis that hemodilution may at least in part explain the inverse relationship between $\mathrm{NP}$ and $\mathrm{Hb}$, we assessed the association of plasma levels of $\mathrm{N}$-Terminal fragment of Pro B-Type Natriuretic Peptide (NT-proBNP) and copeptin with several volumedependent and volume-independent erythrocyte-related parameters in a large populationbased sample of young and healthy individuals. 


\section{Materials and methods}

The 'genetic and phenotypic determinants of blood pressure and other cardiovascular risk factors' (GAPP) study is an ongoing prospective population-based cohort study. Our detailed study methods were published earlier (14). Between 2010 and 2013, all inhabitants of the Principality of Liechtenstein aged between 25 and 41 years were invited to participate in GAPP and 2170 were successfully enrolled in the study. Our main exclusion criteria were prevalent cardiovascular disease, chronic kidney disease, a body mass index (BMI) $>35 \mathrm{~kg} / \mathrm{m}^{2}$, medically treated diabetes mellitus or any other severe illness. In the current analyses, individuals with treated hypertension $(n=35)$ were excluded. A total of 2113 participants $(98.3 \%)$ who had valid determinations of Hb, NT-proBNP and copeptin were finally included for our analysis. The local ethics committee approved our study protocol and all participants provided written informed consent.

\section{Assessment of study variables:}

Baseline examination included standardized assessment of personal, medical, lifestyle and nutritional factors by questionnaires. The individual physical activity questionnaire (IPAQ) was used for the evaluation of the subjects' physical activity (14). Weight and height were measured in a standardized manner and BMI was calculated by dividing weight in kilograms by height in meters squared (14). Smoking status of the participants was self-reported and classified as current, former or never smoking. Conventional office blood pressure (BP) was obtained in triplicate in a quiet environment after at least 5 minutes rest in a sitting position (14). Bioelectrical impedance analysis was used to assess fat and muscle mass as well as body water content of all participants using standardized methodology and a validated device (BIA ego fit, 2010, Germany) (14). 


\section{Blood and urinary samples:}

A fasting venous blood sample was obtained from every subject by a trained study nurse using a minimally traumatic venipuncture. All samples were immediately centrifuged. Plasma levels of NT-proBNP, iron, ferritin, sodium, creatinine and high-sensitive C-reactive protein (hs-CRP) were analyzed on a Roche Cobas 6000 analyzer (F. Hoffmann - La Roche, Switzerland) using fresh blood samples (14). Hb and complete blood count were obtained using the sodium-lauryl-sulphate Hb method (Sysmex XE 5000) (14). Plasma copeptin was directly assayed using an immunoluminometric test (BRAHMS GmbH, Germany) (14). Hct (\%) was assessed using the erythrocyte pulse height detection method of whole erythrocyte count (EC) volume in whole blood. The following indices were calculated according to the following formulas: Mean corpuscular volume (MCV): $10 \times \operatorname{Hct}(\%) / \mathrm{EC}\left(10^{12} / \mathrm{L}\right)$; mean corpuscular $\mathrm{Hb}(\mathrm{MCH}): 10$ x $\mathrm{Hb}(\mathrm{g} / \mathrm{L}) / \mathrm{EC}\left(10^{12} / \mathrm{L}\right)$; mean corpuscular Hb concentration $(\mathrm{MCHC})(\mathrm{g} / \mathrm{L}): 100 \times \mathrm{Hb}(\mathrm{g} / \mathrm{L}) / \mathrm{HC}(\%)$. Females and males with Hb levels below $120 \mathrm{~g} / \mathrm{l}$ and $130 \mathrm{~g} / \mathrm{l}$ respectively where considered to have anemia.

Plasma copeptin levels were measured using a Brahms Luminometry analyzer using fresh blood samples. For the estimation of the glomerular filtration rate (eGFR), we used the creatinine based chronic kidney disease epidemiology collaboration (CKD-EPI) formula (15). Urinary sodium was measured from fresh and fasting spot urine samples using a Roche Cobas 6000 analyzer (F. Hoffmann - La Roche, Switzerland). Sodium urinary excretion was estimated using the previously validated formula by Kawasaki et al (16). The classification of the erythrocytes related parameters on volume-dependent or volume-independent variables was done according to the units of measurement in which they were expressed (17), considering as volume-dependent those that had a volume unit on its denominator (the variable is then relative to a given volume). 


\section{Statistical analysis:}

Baseline characteristics were stratified according to sex. Distribution of continuous variables was assessed using skewness, kurtosis and visual inspection of the histogram. Baseline characteristics of continuous variables were presented as means (standard deviation) or medians (interquartile range) and compared using analysis of variance or Kruskal Wallis tests, as appropriate. Categorical variables were presented as counts (percentages) and compared using chi-square tests.

Due to significant sex differences in NT-proBNP, copeptin and Hb levels, we pre-specified to perform all analyses stratified by sex. We built multivariable linear regression models to calculate the $\beta$-coefficients of $\mathrm{Hb}, \mathrm{Hct}, \mathrm{EC}, \mathrm{MCHC}, \mathrm{MCV}$ and $\mathrm{MCH}$ and across quartiles of NT-proBNP and copeptin, and to adjust for potential confounders. As observed correlations were approximately linear, additional analyses were performed using NT-proBNP and copeptin as continuous log-transformed variables. First, we performed age-adjusted analyses. Multivariable models were additionally adjusted for a common set of pre-defined covariates, including BMI, systolic BP, eGFR, smoking habit, body composition, hs-CRP, education level, physical activity, plasma ferritin and a set of variables related to plasma volume regulation, including estimated fluid intake, plasma osmolality and urinary sodium excretion. Models related to NT-proBNP were additionally adjusted for copeptin levels and vice versa.

Categorical variables were introduced in all multivariable models using binary indicator variables. We used the SAS statistical software version 9.4 (SAS Institute Inc, Cary, NC USA) for all analyses. A p-value of $<0.05$ was pre-specified to indicate statistical significance. 


\section{Results}

\section{Baseline characteristics:}

Sex-specific baseline characteristics of the 2113 participants are presented in Table 1 and Table 2. Median age (interquartile range) was $36.7(31 ; 40)$ years and $54 \%$ of included individuals were females. Median (interquartile range) NT-proBNP and copeptin levels were $49.5(33 ; 80) \mathrm{ng} / \mathrm{L}$ and $2.3(1.6 ; 3.6) \mathrm{pmol} / \mathrm{l}$ among women and $20(11 ; 32) \mathrm{ng} / \mathrm{L}$ and $4.0(2.7$; 5.8) $\mathrm{pmol} / \mathrm{l}$ among men, respectively (all $\mathrm{p}<0.0001$ ). Mean (standard deviation) Hb levels were 130 (9.1) among women and 149.7 (8.6) among men ( $\mathrm{p}<0.0001)$. Across increasing quartiles of NT-proBNP levels, Hb levels were 131.7 (9.8), 130.4 (8.5), 129.5 (9.3) and 128.5 (8.6) $\mathrm{g} / \mathrm{L}$ among women (p<0.0001); and 152.1 (8.3), 150.3 (8.2), 149 (8.4) and 147.2 (8.6) $\mathrm{g} / \mathrm{L}$ among men $(\mathrm{p}<0.0001)$.

\section{$\underline{\text { Relationship between NT-proBNP and erythrocyte-related parameters: }}$}

Results from age- and multivariable adjusted linear regression models for the relationships of NT-proBNP with Hb, Hct, EC, MCHC, MCV and MCH are shown in Table 3 for women and Table 4 for men. These analyses showed a significant inverse relationship of NT-proBNP with $\mathrm{Hb}, \mathrm{Hct}, \mathrm{EC}$ and $\mathrm{MCHC}$ but not with $\mathrm{MCV}$ or $\mathrm{MCH}$. After multivariable adjustment, the $\beta$-regression coefficients (95\% confidence interval (CI)) for $\mathrm{Hb}$, Hct, EC and MCHC were -1.99 (-2.73; -1.26), $\mathrm{p}<0.0001 ;-0.46(-0.67 ;-0.26), \mathrm{p}<0.0001 ;-0.07(-0.09 ;-0.04)$, $\mathrm{p}<0.0001$ and $-1.17(-1.91,-0.43) \mathrm{p}=0.002$, respectively among women, and $-1.68(-2.36$; $1.01), \mathrm{p}<0.0001 ;-0.38(-0.57 ;-0.20), \mathrm{p}<0.0001 ;-0.06(-0.09 ;-0.04), \mathrm{p}<0.0001$ and $-0.78(-$ $1.50 ;-0.07), \mathrm{p}=0.03$, respectively among men. In contrast, no significant relationships were observed between NT-proBNP and MCV ( $\beta$-regression coefficient (95\% CI): 0.25 (-0.11; $0.62), \mathrm{p}=0.18$ among women and $0.26(-0.04 ; 0.56), \mathrm{p}=0.09$ among men $)$ or $\mathrm{MCH}(\beta-$ 
regression coefficient $(95 \% \mathrm{CI}):-0.02(-0.16 ; 0.13), \mathrm{p}=0.83$ among women and $0.03(-0.08$; 0.14), $\mathrm{p}=0.61$ among men).

\section{$\underline{\text { Relationship between copeptin and erythrocyte-related parameters: }}$}

Findings from age- and multivariable adjusted linear regression analyses for the relationship of copeptin with $\mathrm{Hb}, \mathrm{Hct}, \mathrm{EC}, \mathrm{MCHC}, \mathrm{MCV}$ and $\mathrm{MCH}$ are shown in Table 5 for women and Table 6 for men. These analyses showed an approximately linear, direct relationship of copeptin with $\mathrm{Hb}$, Hct and EC but not with $\mathrm{MCHC}$, MCV or MCH. After multivariable adjustment, the $\beta$-regression coefficients $(95 \% \mathrm{CI})$ for $\mathrm{Hb}$, Hct and EC were 0.77 (-0.01; $1.54), p=0.05 ; 0.25(0.03 ; 0.46), p=0.03$ and $0.04(0.01 ; 0.07), p=0.007$, respectively among women, and $1.36(0.39 ; 2.32), \mathrm{p}=0.006 ; 0.41(0.15 ; 0.68), \mathrm{p}=0.002$ and $0.06(0.02 ; 0.09)$, $\mathrm{p}=0.002$, respectively among men. No significant relationships were observed between copeptin and either MCHC ( $\beta$-regression coefficient $(95 \% \mathrm{CI}):-0.07(-0.85 ; 0.71), \mathrm{p}=0.86$ among women and -0.17 (-1.19; 0.86), $\mathrm{p}=0.75$ among men), MCV ( $\beta$-regression coefficient $(95 \% \mathrm{CI})):-0.16(-0.54 ; 0.23), \mathrm{p}=0.43$ among women and $-0.12(-0.55 ; 0.31), \mathrm{p}=0.58$ among men) or $\mathrm{MCH}(\beta$-regression coefficient $(95 \% \mathrm{CI}):-0.07(-0.22 ; 0.08), \mathrm{p}=0.39$ among women and $-0.05(-0.21 ; 0.10), \mathrm{p}=0.51$ among men.

A graphic representation of the Pearson correlation between NT-proBNP or copeptin (Y-axis) and hemoglobin is presented below (Figure $1(A, B)$ ). Pearson coefficients (R coefficient) for the above mentioned correlations were: $-0.507(\mathrm{p}<0.0001)$ for the correlation between NTproBNP and $\mathrm{Hb}$ and $0.343(\mathrm{p}<0.0001)$ for the correlation between copeptin and $\mathrm{Hb}$. 


\section{Discussion}

In this large population-based study, NT-proBNP levels were significantly and inversely associated with $\mathrm{Hb}, \mathrm{Hct}, \mathrm{EC}$ and MCHC but not with MCV or MCH. Similar associations were observed for copeptin although the direction of the association was opposite. In both cases, the great majority of the observed associations remained significant after adjustment for a broad set of potential confounders. NP and vasopressin are directly involved in the regulation of intravascular volume by promoting antagonistic actions $(4,7,12)$. While NP increase kidney blood flow and filtration with concomitant natriuresis and diuresis, vasopressin increases water permeability of kidney collecting duct by inducing translocation of aquaporin-cd water channels to plasma membrane, which results in water retention. Therefore, a direct correlation between volume-dependent erythrocyte-related parameters and markers related to vasopressin metabolism, such as copeptin, as well as an indirect correlation between volume-dependent erythrocyte-related parameters and a NP representative, such as NT-proBNP, suggest that intravascular volume status may explain our findings. In contrast, there was no association of the volume-independent erythrocyte-related parameters $(\mathrm{MCV}$ and $\mathrm{MCH})$ with either NT-proBNP or copeptin. Therefore, our data suggest that hemodilution may at least in part be responsible for the previously observed inverse relationship between NP and $\mathrm{Hb}(8-10)$.

\section{Strengths and limitations:}

A major strength of our study is its population based-design and the availability of a large and well-characterized cohort of young and healthy participants. Furthermore, we included subjects without overt cardiovascular disease or diabetes mellitus, which lowers the potential for confounding by co-morbidities. Limitations which need to be taken into account when 
interpreting our results are the following: First, the cross-sectional design of this study does not allow making causal inferences, second, our study cohort mainly consisted of white adults and the generalizability to other populations remains uncertain; third, as Porat O. et al demonstrated: erythropoietin stimulates atrial natriuretic peptide secretion from adult rat cardiac atrium (18). Since erythropoietin wasn't measured in our study, we were not able to test the influence of this parameter on our results. Fourth, NT-proBNP is the currently best validated and therefore preferred biomarker for the quantification of hemodynamic stress in studies using frozen samples (19). In contrast to B-Type Natriuretic Peptide (BNP), it has very high pre-analytical stability. It is known, that the NT-proBNP assay used in this study, shows some cross-reactivity with Pro B-Type Natriuretic Peptide (proBNP) (20). However, it allows quantifying hemodynamic stress also in the normal range and is accordingly used also for screening purposes (21). As the blood concentration of A-Type Natriuretic Peptide is much higher than that of BNP, it is conceivable that additional measurement of mid-regional Pro A-Type Natriuretic Peptide (22) in our study might have provided additional insights. Fifth, the observed differences between the quartiles for the erythrocyte-related parameters are, even though significant, relatively small. This might potentially be explained by day-today differences in hydration rather than by the manifestation of a chronic aspect. However, venipunctures were done under standardized conditions, which would minimize this issue. Sixth, the high biological variability of BNP expression (23) could also have an influence on some of the results (Table 3 and 4). However, if this variability would have a significant influence, we would expect that our results would have been biased towards the null. Seventh, erythrocyte volume might also be affected by changes in blood volume. However, we assume that the changes in blood volume promoted by both natriuretic peptides and vasopressin in our study population are physiological. Because red blood cell distribution 
width (RDW) has also been related to the occurrence of cardiovascular events (24), it would have been interesting to assess the relationships of RDW with NT-proBNP and copeptin. Unfortunately, RDW is unavailable in our study cohort.

\section{Conclusion:}

We found an independent inverse relationship between NT-proBNP levels and several volume-dependent but not volume-independent erythrocyte parameters in a large population based cohort of 2113 young and healthy adults. These relationships were similar but opposite in direction for copeptin, a vasopressin related hormone. Our results therefore suggest that hemodilution may at least in part explain the inverse association between $\mathrm{Hb}$ and NTproBNP. Further studies to investigate the relevance of these findings in clinical practice are needed. 


\section{Acknowledgments}

No other persons have made substantial contributions to this manuscript.

\section{Funding sources}

The GAPP study was supported by the Liechtenstein Government, the Commission for Technology and Innovation, the Swiss Heart Foundation, the Swiss Society of Hypertension, the University of Basel, the University Hospital Basel, the Hanela Foundation, Schiller AG and Novartis. David Conen was supported by a grant of the Swiss National Science Foundation (PP00P3_133681).

\section{Disclosures}

All authors have approved the final article. Conflicts of interest: None declared 


\section{References}

1. Karabulut A, Kaplan A, Aslan C, Iltumur K, Toprak G, Toprak N. The association between nt-probnp levels, functional capacity and stage in patients with heart failure. Acta Cardiol. 2005;60:631-638.

2. Kragelund C, Gronning B, Kober L, Hildebrandt P, Steffensen R. N-terminal pro-btype natriuretic peptide and long-term mortality in stable coronary heart disease. $N$ Engl $J$ Med. 2005;352:666-675.

3. Maisel A, Mueller C, Adams K, Jr., Anker SD, Aspromonte N, Cleland JG, et al. State of the art: Using natriuretic peptide levels in clinical practice. Eur J Heart Fail. 2008;10:824-839.

4. de Bold AJ, Borenstein HB, Veress AT, Sonnenberg H. A rapid and potent natriuretic response to intravenous injection of atrial myocardial extract in rats. Reprinted from life sci. 28:89-94, 1981. J Am Soc Nephrol. 2001;12:403-409.

5. Sudoh T, Kangawa K, Minamino N, Matsuo H. A new natriuretic peptide in porcine brain. Nature. 1988;332:78-81.

6. Dhingra H, Roongsritong C, Kurtzman NA. Brain natriuretic peptide: Role in cardiovascular and volume homeostasis. Semin Nephrol. 2002;22:423-437.

7. Marcus LS, Hart D, Packer M, Yushak M, Medina N, Danziger RS, et al. Hemodynamic and renal excretory effects of human brain natriuretic peptide infusion in patients with congestive heart failure. A double-blind, placebo-controlled, randomized crossover trial. Circulation. 1996;94:3184-3189. 
8. Fukuta H, Ohte N, Mukai S, Saeki T, Kobayashi K, Kimura G. Anemia is an independent predictor for elevated plasma levels of natriuretic peptides in patients undergoing cardiac catheterization for coronary artery disease. Circ J: official journal of the Japanese Circulation Society. 2008;72:212-217.

9. Nybo M, Benn M, Mogelvang R, Jensen JS, Schnohr P, Rehfeld JF, et al. Impact of hemoglobin on plasma pro-b-type natriuretic peptide concentrations in the general population. Clin Chem. 2007;53:1921-1927.

10. Tsuji H, Nishino N, Kimura Y, Yamada K, Nukui M, Yamamoto S, et al. Haemoglobin level influences plasma brain natriuretic peptide concentration. Acta Cardiol. 2004;59:527-531.

11. Anand IS, Kuskowski MA, Rector TS, Florea VG, Glazer RD, Hester A, et al. Anemia and change in hemoglobin over time related to mortality and morbidity in patients with chronic heart failure: Results from val-heft. Circulation. 2005;112:1121-1127.

12. Nielsen S, Chou CL, Marples D, Christensen EI, Kishore BK, Knepper MA. Vasopressin increases water permeability of kidney collecting duct by inducing translocation of aquaporin-cd water channels to plasma membrane. P Natl Acad Sci USA. 1995;92:10131017.

13. Morgenthaler NG, Struck J, Alonso C, Bergmann A. Assay for the measurement of copeptin, a stable peptide derived from the precursor of vasopressin. Clin Chem. 2006;52:112-119 
14. Conen D, Schon T, Aeschbacher S, Pare G, Frehner W, Risch M, et al. Genetic and phenotypic determinants of blood pressure and other cardiovascular risk factors (gapp). SMW. 2013;143:w13728.

15. Levey AS, Stevens LA, Schmid CH, Zhang YL, Castro AF 3rd, Feldman HI, et al. Ckd EPI. A new equation to estimate glomerular filtration rate. Ann Intern Med. 2009;150:604-612.

16. Mente A, O'Donnell MJ, Dagenais G, Wielgosz A, Lear SA, McQueen MJ, et al. Validation and comparison of three formulae to estimate sodium and potassium excretion from a single morning fasting urine compared to 24-h measures in 11 countries. $J$ Hypertens. 2014;32:1005-1014.

17. Greer JP, Foerster J, Rodgers GM, Paraskevas F, Glader B, Arber DA, Mears RT. Red Blood Cell Analytic Parameters. Wintrobe's Clinical Hematology. 2009; Part 1, Chapter 1: 35.

18. Porat O, Neumann D, Zamir O, Nachshon S, Feigin E, Cohen J, et al. Erythropoietin stimulates atrial natriuretic peptide secretion from adult rat cardiac atrium. J Pharmacol Exp Ther. 1996;276(3):1162-8.

19. Thygesen K, Mair J, Mueller C, Huber K, Weber M, Plebani M, et al. Recommendations for the use of natriuretic peptides in acute cardiac care: a position statement from the Study Group on Biomarkers in Cardiology of the ESC Working Group on Acute Cardiac Care. Study Group on Biomarkers in Cardiology of the ESC Working Group on Acute Cardiac Care. Eur Heart J. 2012 Aug;33(16):2001-6. 
20. Luckenbill KN, Christenson RH, Jaffe AS, Mair J, Ordonez-Llanos J, Pagani F, et al. Cross-reactivity of BNP, NT-proBNP, and proBNP in commercial BNP and NT-proBNP assays: preliminary observations from the IFCC Committee for Standardization of Markers of Cardiac Damage. Clin Chem. 2008;54(3):619-21.

21. Thygesen K, Mair J, Mueller C, Huber K, Weber M, Plebani M, et al.

Recommendations for the use of natriuretic peptides in acute cardiac care: a position statement from the Study Group on Biomarkers in Cardiology of the ESC Working Group on Acute Cardiac Care.; Study Group on Biomarkers in Cardiology of the ESC Working Group on Acute Cardiac Care. Eur Heart J. 2012 Aug;33(16):2001-6

22. Maisel A, Mueller C, Nowak R, Peacock WF, Landsberg JW, Ponikowski P, et al. Mid-region pro-hormone markers for diagnosis and prognosis in acute dyspnea: results from the BACH (Biomarkers in Acute Heart Failure) trial. J Am Coll Cardiol. 2010; 55: 20622076.

23. Conen D, Pfisterer M, Martin B. Substantial intraindividual variability of BNP concentrations in patients with hypertension. J Hum Hypertens. 2006 Jun; 20(6): 387-91.

24. Wan H, Yang Y, Zhu J, Huang B, Wang J, Wu S, et al. The relationship between elevated red cell distribution width and long-term outcomes among patients with atrial fibrillation. Clin Biochem. 2015 Aug;48(12):762-7. 

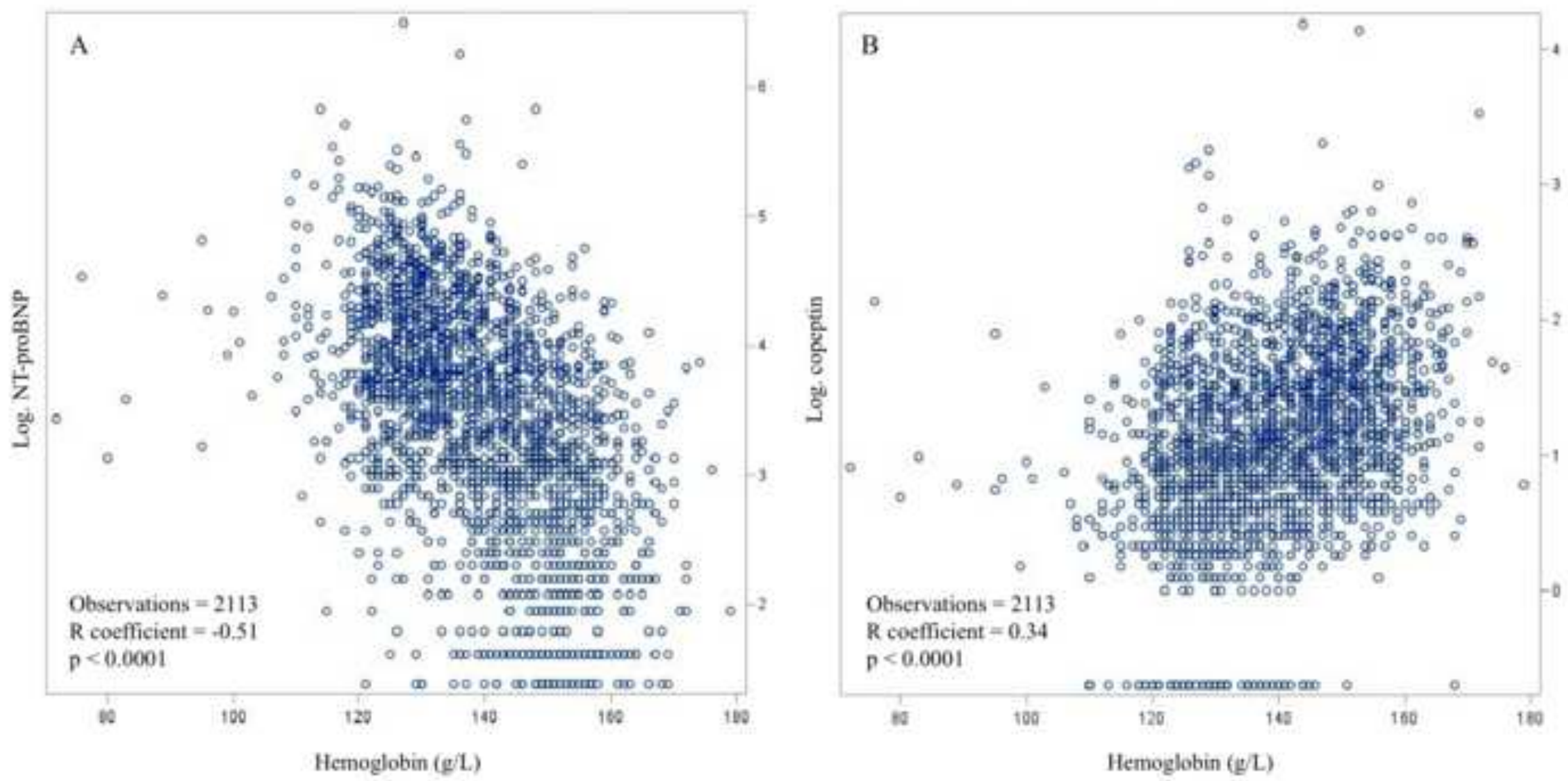

Graphical representation of the Person correlation for the $\log$. NT-prBNP (A) or log copeptin (B) (Y-axis) and hemoglobin (X-axis). R coefficient indicates the Pearson correlation coefficient. 
Table 1 Sex-specific baseline characteristics of the study population

\begin{tabular}{|c|c|c|}
\hline & Women $(n=1136)$ & Men (n=977) \\
\hline Age (years) & $36.7(31-40)$ & $36.7(31-40)$ \\
\hline NT-proBNP (ng/L) & $49.5(33-80)$ & $20(11-32)$ \\
\hline Copeptin (pmol/L) & $2.3(1.6-3.6)$ & $4.0(2.7-5.8)$ \\
\hline \multicolumn{3}{|l|}{ Education $^{*}$} \\
\hline Elementary & $103(9.1)$ & $60(6.1)$ \\
\hline Secondary & 677 (59.6) & $511(52.3)$ \\
\hline Superior & $335(29.5)$ & $378(38.7)$ \\
\hline Alcohol intake (gr/d) & $0(0-0.8)$ & $1.4(0-3)$ \\
\hline \multicolumn{3}{|l|}{ Smoking status } \\
\hline Current & 215 (18.9) & $249(25.5)$ \\
\hline Past & 257 (22.6) & $232(23.8)$ \\
\hline Never & $662(58.3)$ & $495(50.7)$ \\
\hline Physical activity (min/week) & $120(40-270)$ & $190(60-450)$ \\
\hline BMI $\left(\mathrm{kg} / \mathrm{cm}^{2}\right)$ & $23.3 \pm 3.7$ & $25.8 \pm 3.1$ \\
\hline \multicolumn{3}{|l|}{ Body composition (\%) } \\
\hline Fat mass & $28.8 \pm 4.8$ & $20.6 \pm 5.3$ \\
\hline Muscle mass & $33.3 \pm 3.6$ & $37.6 \pm 3.4$ \\
\hline Body water & $52.1 \pm 4.9$ & $57.3 \pm 4.5$ \\
\hline Water intake (L/d) & $1.5(1.5-2.0)$ & $2.0(1.5-2.5)$ \\
\hline Ferritin (ug/L) & $46(28-79)$ & $177(113-262)$ \\
\hline hs-CRP (mg/L) & $0.9(0.5-2.0)$ & $0.9(0.5-1.8)$ \\
\hline Systolic BP (mmHg) & $113.3 \pm 10.1$ & $127.3 \pm 10.9$ \\
\hline
\end{tabular}

Data are mean \pm standard deviation, median (interquartile range) or number (percentage), as appropriate.BMI indicates body mass index; BP, blood pressure; hs-CRP, high sensitive Creactive protein.

*= Educational level of 49 participants was not available. 
Table 2. Sex-specific erythrocytes-related baseline characteristics of the study population

\begin{tabular}{lll}
\hline & Women $(\mathbf{n}=1136)$ & Men $(\mathbf{n}=977)$ \\
\hline Hemoglobin (g/L) & $130 \pm 9.1$ & $149.7 \pm 8.6$ \\
Erythrocyte count $\left(\mathbf{1 0} \mathbf{1 2}^{\mathbf{L}} \mathbf{L}\right)$ & $4.5 \pm 0.3$ & $5.1 \pm 0.31$ \\
Hematocrit (\%) & $38.7 \pm 2.5$ & $43.6 \pm 2.3$ \\
MCHC (g/L) & $336.1 \pm 8.8$ & $343.4 \pm 8.8$ \\
MCV (fL) & $87.1 \pm 4.3$ & $86.2 \pm 3.7$ \\
MCH (10-12/g) & $29.3 \pm 1.7$ & $29.6 \pm 1.4$ \\
Anemia [number; $(\boldsymbol{\%})]$ & $93(8.2)$ & $15(1.5)$ \\
\hline
\end{tabular}

Data are mean \pm standard deviation or number (percentage), as appropriate. $\mathrm{MCH}$ indicates mean corpuscular hemoglobin; $\mathrm{MCV}$, mean corpuscular volume and $\mathrm{MCHC}$, mean corpuscular hemoglobin concentration. 
Table 3 Multivariable regression analyses for the relationship between N-terminal pro-B-type natriuretic peptide and several erythrocyterelated parameters among women

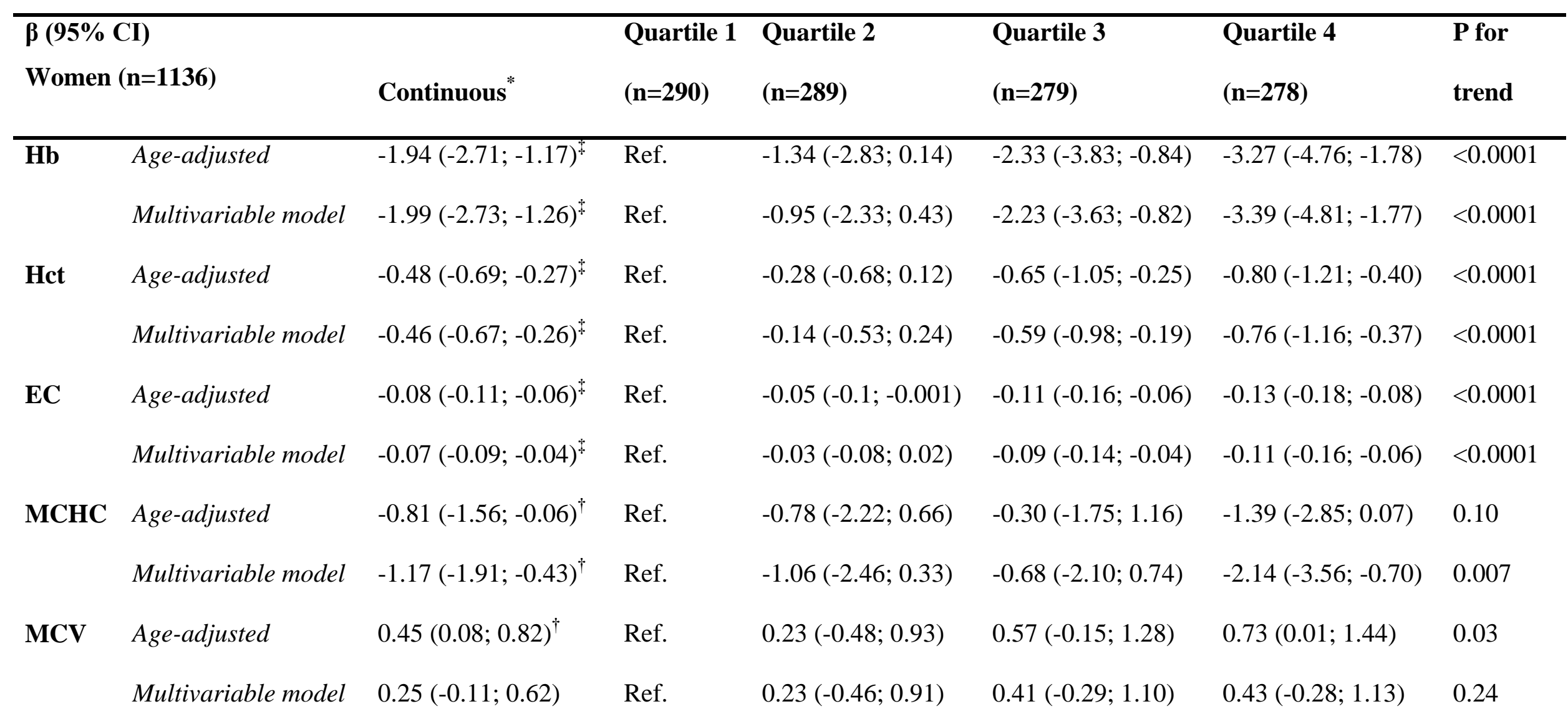




$\begin{array}{llllllll}\text { MCH } & \text { Age-adjusted } & 0.08(-0.07 ; 0.23) & \text { Ref. } & -0.02(-0.30 ; 0.26) & 0.16(-0.12 ; 0.44) & 0.11(-0.17 ; 0.39) & 0.31 \\ & \text { Multivariable model } & -0.02(-0.16 ; 0.13) & \text { Ref. } & -0.04(-0.31 ; 0.23) & 0.08(-0.19 ; 0.35) & -0.05(-0.32 ; 0.22) & 0.84\end{array}$

$\beta$ indicates regression coefficient; CI, confidence interval; EC, Erythrocyte count (10 $/ 2 / \mathrm{L}) ; \mathrm{Hb}$, hemoglobin (g/L); Hct, hematocrit (\%); MCH,

mean corpuscular $\mathrm{Hb}\left(10^{-12} / \mathrm{g}\right)$; MCHC, mean corpuscular Hb concentration (g/L) and MCV, mean corpuscular volume (fL).

*= NT-proBNP and copeptine were log transformed for continuous analyses

$\dagger=\mathrm{p}<0.05$

$t=p<0.0001$

Multivariable models were adjusted for age, systolic blood pressure, body mass index, smoking, estimated glomerular filtration rate, education,

physical activity, body composition, high sensitive C-reactive protein, ferritin, estimated fluid intake, plasma osmolarity, sodium urinary

excretion and copeptin (missing: 73). 
Table 4 Multivariable regression analyses for the relationship between N-terminal pro-B-type natriuretic peptide and several erythrocyterelated parameters among men

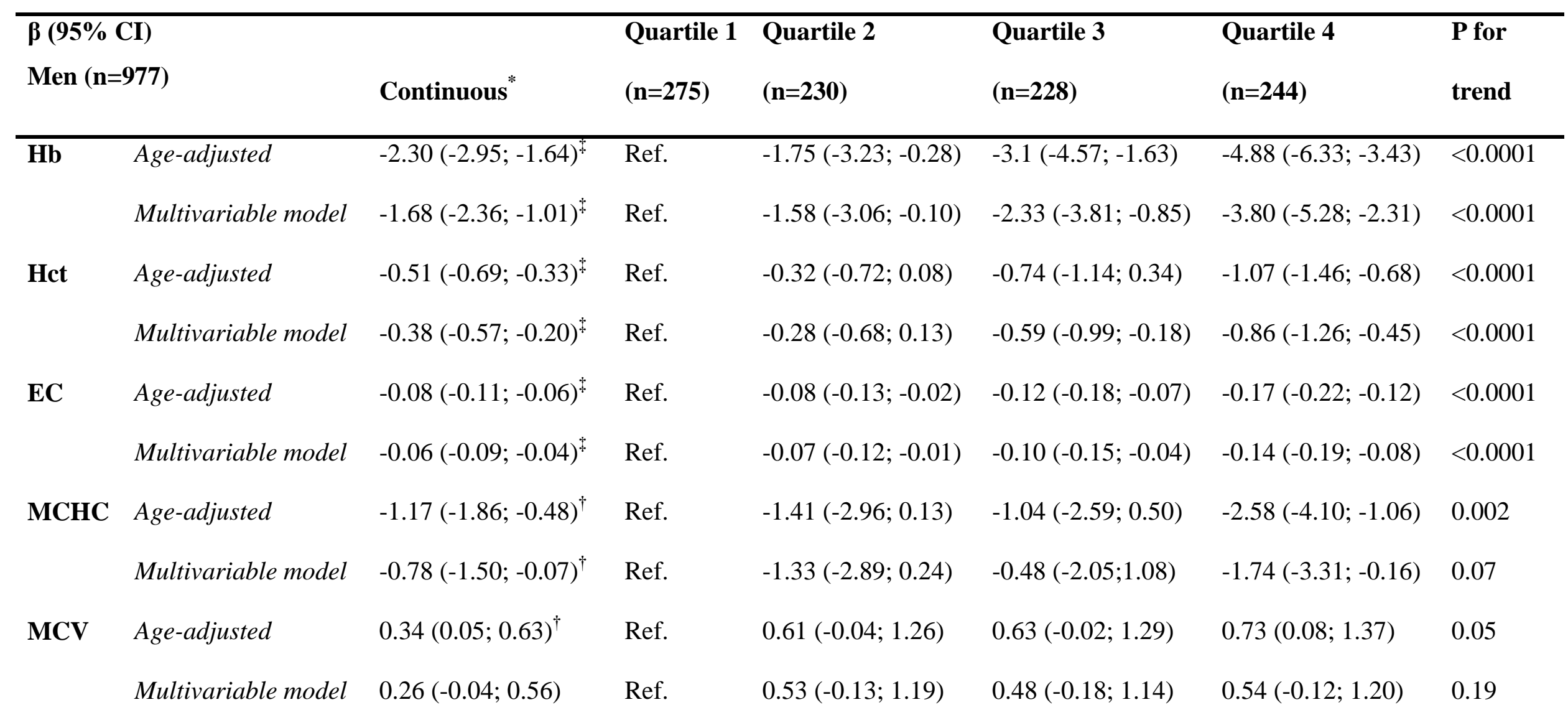




$\begin{array}{llllllll}\text { MCH } & \text { Age-adjusted } & 0.02(-0.08 ; 0.13) & \text { Ref. } & 0.08(-0.16 ; 0.32) & 0.11(-0.13 ; 0.35) & 0.05(-0.18 ; 0.29) & 0.75 \\ & \text { Multivariable model } & 0.03(-0.08 ; 0.14) & \text { Ref. } & 0.06(-0.18 ; 0.30) & 0.10(-0.14 ; 0.34) & 0.06(-0.18 ; 0.30) & 0.69\end{array}$

$\beta$ indicates regression coefficient; CI, confidence interval; EC, Erythrocyte count (10 $/ 2 / \mathrm{L}) ; \mathrm{Hb}$, hemoglobin (g/L); Hct, hematocrit (\%); MCH,

mean corpuscular $\mathrm{Hb}\left(10^{-12} / \mathrm{g}\right)$; MCHC, mean corpuscular Hb concentration (g/L) and MCV, mean corpuscular volume (fL).

*= NT-proBNP and copeptine were log transformed for continuous analyses

$\dagger=\mathrm{p}<0.05$

$t=p<0.0001$

Multivariable models were adjusted for age, systolic blood pressure, body mass index, smoking, estimated glomerular filtration rate, education,

physical activity, body composition, high sensitive C-reactive protein, ferritin, estimated fluid intake, plasma osmolarity, sodium urinary

excretion and copeptin(missing: 49). 
Table 5 Multivariable regression analyses for the relationship between copeptin and several erythrocyte-related parameters among women

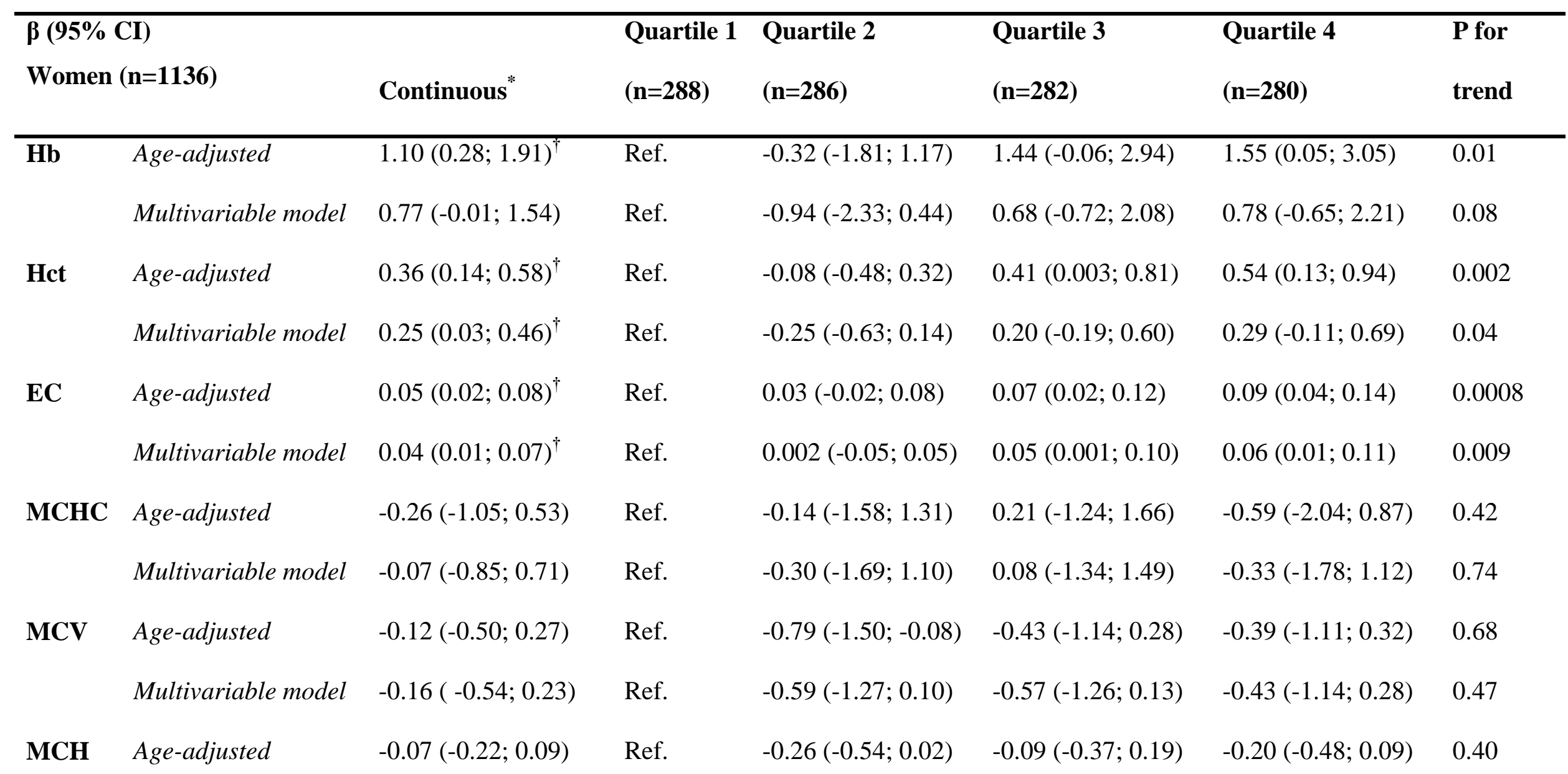




\section{Multivariable model $\quad-0.07(-0.22 ; 0.08)$ \\ Ref. \\ $-0.20(-0.47 ; 0.06)$ \\ $-0.14(-0.42 ; 0.13)$ \\ $-0.18(-0.46 ; 0.09)$

$\beta$ indicates regression coefficient; CI, confidence interval; EC, Erythrocyte count (10 $12 / \mathrm{L}) ; \mathrm{Hb}$, hemoglobin (g/L); Hct, hematocrit (\%); MCH, mean corpuscular $\mathrm{Hb}\left(10^{-12} / \mathrm{g}\right)$; MCHC, mean corpuscular Hb concentration $(\mathrm{g} / \mathrm{L})$ and MCV, mean corpuscular volume (fL).

*= NT-proBNP and copeptine were log transformed for continuous analyses

$\dagger=p<0.05$

$\ddagger=p<0.0001$

Multivariable models were adjusted for age, systolic blood pressure, body mass index, smoking, estimated glomerular filtration rate, education, physical activity, body composition, high sensitive C-reactive protein, ferritin, estimated fluid intake, plasma osmolarity, sodium urinary excretion and NT-proBNP (missing: 73). 
Table 6 Multivariable regression analyses for the relationship between copeptin and several erythrocyte-related parameters among men

\begin{tabular}{|c|c|c|c|c|c|c|c|}
\hline \multicolumn{3}{|c|}{$\overline{\beta(95 \% ~ C I)}$} & Quartile 1 & Quartile 2 & Quartile 3 & Quartile 4 & $P$ for \\
\hline \multicolumn{2}{|c|}{ Men (n=977) } & Continuous ${ }^{*}$ & $(n=258)$ & $(n=230)$ & $(n=245)$ & $(n=244)$ & trend \\
\hline $\mathbf{H b}$ & Multivariable model & $1.36(0.39 ; 2.32)^{\dagger}$ & Ref. & $0.57(-0.92 ; 2.05)$ & $1.10(-0.39 ; 2.60)$ & $1.64(0.08 ; 3.19)$ & 0.04 \\
\hline Het & Age-adjusted & $0.51(0.26 ; 0.76)^{\ddagger}$ & Ref. & $0.17(-0.24 ; 0.58)$ & $0.32(-0.08 ; 0.72)$ & $0.67(0.27 ; 1.07)$ & 0.0008 \\
\hline \multirow[t]{2}{*}{ EC } & Age-adjusted & $0.06(0.03 ; 0.10)^{\dagger}$ & Ref. & $0.01(-0.04 ; 0.07)$ & $0.05(-0.01 ; 0.10)$ & $0.07(0.02 ; 0.13)$ & 0.004 \\
\hline & Multivariable model & $0.06(0.02 ; 0.09)^{\dagger}$ & Ref. & $0.03(-0.03 ; 0.08)$ & $0.06(0.003 ; 0.11)$ & $0.06(0.007 ; 0.12)$ & 0.02 \\
\hline МCHC & Age-adjusted & $-0.25(-1.21 ; 0.71)$ & Ref. & $0.33(-1.24 ; 1.91)$ & $0.18(-1.37 ; 1.73)$ & $-0.28(-1.83 ; 1.27)$ & 0.61 \\
\hline MCV & Multivariable model & $-0.12(-0.55 ; 0.31)$ & Ref. & $-0.14(-0.79 ; 0.52)$ & $-0.40(-1.06 ; 0.27)$ & $-0.06(-0.75 ; 0.64)$ & 0.87 \\
\hline МCH & Age-adjusted & $-0.02(-0.17 ; 0.12)$ & Ref. & $0.06(-0.18 ; 0.30)$ & $-0.11(-0.35 ; 0.13)$ & $0.01(-0.23 ; 0.25)$ & 0.88 \\
\hline
\end{tabular}


Multivariable model $\quad-0.05(-0.21 ; 0.10) \quad$ Ref. $\quad-0.05(-0.29 ; 0.19) \quad-0.16(-0.40 ; 0.08) \quad-0.05(-0.30 ; 0.20) \quad 0.66$

$\beta$ indicates regression coefficient; CI, confidence interval; EC, Erythrocyte count (10 $/ 2 / \mathrm{L}) ; \mathrm{Hb}$, hemoglobin (g/L); Hct, hematocrit (\%); MCH,

mean corpuscular $\mathrm{Hb}\left(10^{-12} / \mathrm{g}\right)$; MCHC, mean corpuscular Hb concentration (g/L) and MCV. mean corpuscular volume (fL).

*= NT-proBNP and copeptine were log transformed for continuous analyses

$\dagger=\mathrm{p}<0.05$

$\ddagger=p<0.0001$

Multivariable models were adjusted for age, systolic blood pressure, body mass index, smoking, estimated glomerular filtration rate, education, physical activity, body composition, high sensitive C-reactive protein, ferritin, estimated fluid intake, plasma osmolarity, sodium urinary excretion and NT-proBNP (missing: 49). 


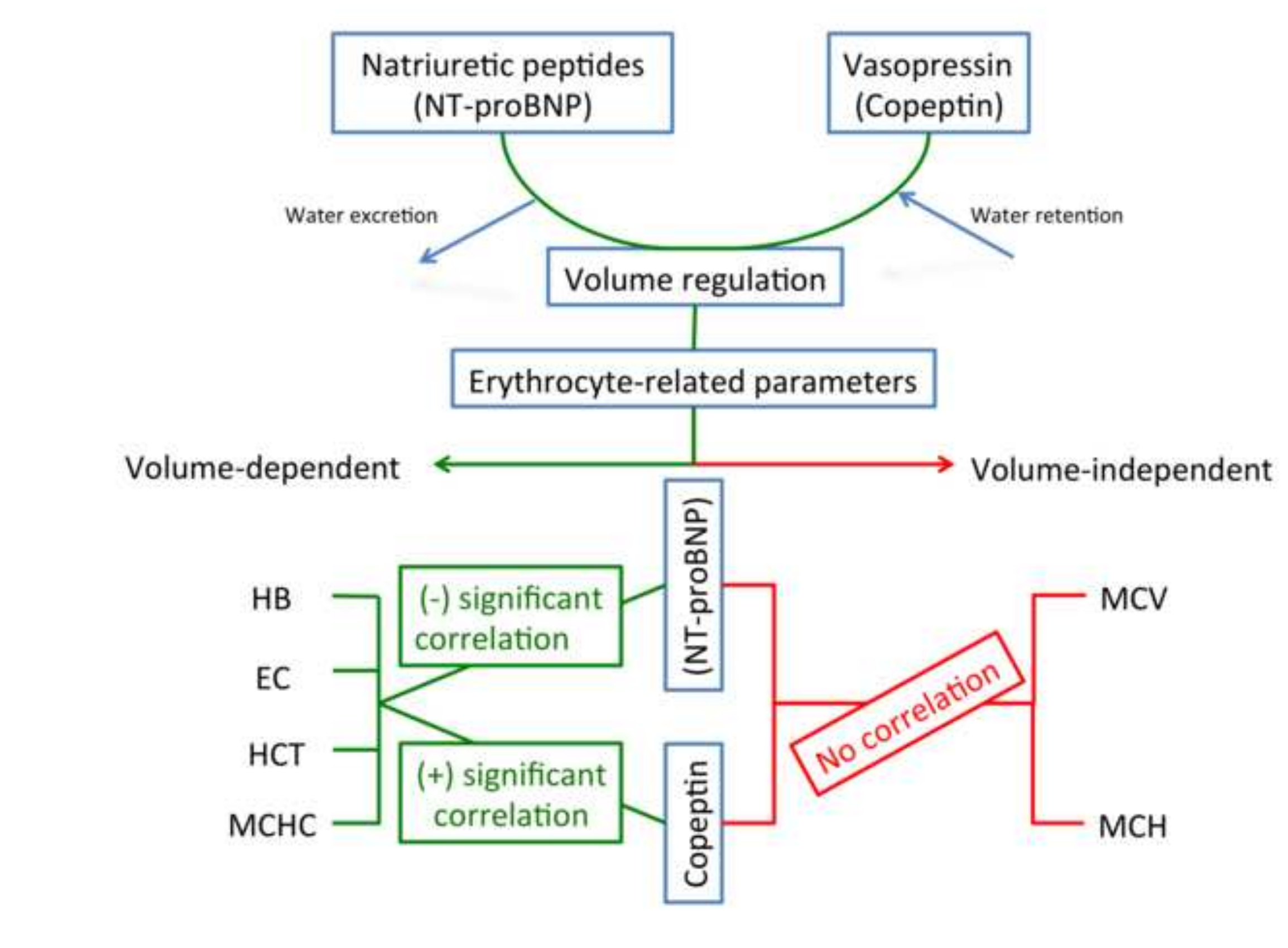

